\title{
Universal Properties of Intonation Components
}

\author{
Zeynep Muslimovna Bazarbayeva ${ }^{1}$, Akshaim Maksutovna Zhalalova ${ }^{1} \&$ Yenlik Nurlanovna Ormakhanova ${ }^{1}$ \\ ${ }^{1}$ A. Baitursynov Institute of Linguistics, Ministry of Education and Science of the Republic of Kazakhstan, \\ Almaty, Kazakhstan \\ Correspondence: Zeynep Muslimovna Bazarbayeva, Kurmangazy Str., 29, Almaty, 050010, Republic of \\ Kazakhstan
}

$\begin{array}{lcc}\text { Received: February 28, } 2015 & \text { Accepted: March 20, } 2015 \quad \text { Online Published: April 26, } 2015 \\ \text { doi:10.5539/res.v7n6p226 } & \text { URL: http://dx.doi.org/10.5539/res.v7n6p226 }\end{array}$

\begin{abstract}
The article so proposed summarizes the results of the experimental \& phonetic research of sounding speech intonation based on the material of the French, Kazakh and Russian languages. It considers intonation component functions (of melodics, duration, and intensity). A set of prosodic means is identified that convey the intonational specifics of sounding speech, and the relevant intonational components in interconnection and in combination that participate in the differentiation of utterances. Universal properties of intonation components, linguistic meanings as well as their role in the presentation of sounding speech are determined. The results of the research are based on the experimental data, and on the generalization of general provisions of the theory of intonation in the light of the current trends of general linguistics.
\end{abstract}

Keywords: intonation, melodics, duration, intensity, tempo, logical emphasis, tone register, timbre, speech flow, and rising, falling, rising-falling, and falling-rising melodics, experimental analysis, universal properties, division of the speech flow, range, interval, pause, and voiced pause

\section{Introduction}

Connected sounding speech cannot be imagined without quite a number of its inherent properties: Change in melodics (nuclear voice tone) and in duration, tempo, pause, intensity and timbre. Not all of these constant features are equally perceived by the human being, and not all of them play the equal role in the speech flow arrangement. The intonation components, or prosodic features, as they are called, act in the oral speech in close interconnection and cohesion, and their various combinations serve for the presentation of an utterance, or a text (Hart, 2006).

Melodics is deemed to be the main and universal intonation component in the most different languages. "The universality of a pitch intonation component makes itself evident also in the fact that melodics is used as the most important intonational means in the most different languages, and that within one language the melodics perform different functions of intonation. It is facilitated not only by the low degree of the availability of melodics at a segmental level but also by a great deal of distinctive capabilities in the said intonation component" (Svetozarova, 1982).

The peculiarity of each language makes itself evident to a greater degree in melodics (change in the pitch of a voice), and it is no mere chance that there is an expression "language melodics". The melodics can perform different functions (Alkon, 1959). Along with a pause, it is used for the division of speech and for the linking of its parts as well. Together with lexical and grammatical means, it participates in the conveying of the meaning. The melodics is the most important means to distinguish communicative types of utterances (story, order, question, exclamation). Along with a syntagmatic emphasis and timbre, it is used for the exact conveying of a logical aspect of oral speech and its emotional colors. The melodics may change depending on individual peculiarities of oral speech of individual speakers thereof, but there are basic forms of melodics, which are typical of people speaking one language. If these melodic models are not adhered to, speech may be incomprehensible.

\section{Methods}

A method of structural analysis of intonation is widely applied in present-day experimental and phonetic works. This method providing for the integral analysis of all interrelated components of intonation, the study and description of distribution of physical characteristics (nuclear tone frequency, intensity and duration) was 
developed and introduced by Russian scientists. Auditing and instrumental methods of research as well as computer processing of data have been used in the work.

\section{Results}

Acoustically melodic features of speech are correlated with the time-varying nuclear tone frequency (NTF). When talking, constant changes in the NTF value occur. The NTF values may unessentially change subject to individual sounds and sound combinations since the own physical features are peculiar to speech sounds, which depend on their spectral characteristics (Bolinger, 1970). In different languages, the tone contour may change under the influence of syntagmatic and logical emphases, i.e., of the most important word accentuated by the meaning. The direction of the NTF contour often acts as a distinctive feature of an utterance, which may be rising, falling, rising \& falling, falling \& rising and even.

In addition to the general direction of the main tone, the acoustic (secondary) parameters such as melodic (tone) intervals, ranges, and registers (levels) may act as a relevant characteristic (Danesh, 1960).

In the linguistic literature, the interval means a value of downturn or upturn in a syllable and between the syllables and should be defined by the ratio between the maximum and minimum values of the nuclear tone frequency in this part. The interval is characterized by the direction, which may be rising, failing and even. For example, the intonation of story-telling in different languages, in case of the similarity of direction of moving the nuclear tone frequency differs in minor tone intervals from the intonation of order or exclamation.

Positive and negative frequency intervals are distinguished. The frequency interval is called positive if the first measurable value of the nuclear tone frequency is lower than the second one. Otherwise, i.e., if the first of the comparable values is higher than the second one, the frequency interval should be deemed to be negative. For example, it was proved by the experimental and phonetic method that the intonation of interposition parenthetic units in the Kazakh and French languages is characterized by the negative tone intervals on both junctures with the principal sentence. In the Russian language, in most cases the first juncture is presented due to the negative tone intervals, and the second one - due to the positive tone intervals.

A key role in the determination of the extent of importance of syntagms is played by the frequency ranges. A range should be determined by the difference between the maximum and minimum NTF values in the part being analyzed. Mean, extended and narrowed ranges are distinguished. The emotionally saturated utterances are usually characterized by the extended frequency ranges. For example, in many languages, exclamatory sentences as well as imperative sentences with the meaning of an order have more extended tone ranges as compared to other communicative types. Subject to the value, the frequency ranges may to be indicative of the basic or secondary idea in sentences with parenthetic units. Thus, parenthetic structures in different languages are, irrespective of their positions, characterized by the narrowed tone ranges in comparison with the principal composition of a sentence.

In the intonation characteristic of the segment being analyzed, a substantial role is played by the tone (midfrequency) level or register. For example, if melodic contours are similar, imperative sentences are realized on higher tone levels than narrative ones. In the French, Kazakh and Russian languages, parenthetic units in the interposition and the postposition are characterized by the lower tone levels than the principal composition of a sentence. The higher midfrequency levels are indicative of the semantic importance of the segments analyzed, and the lower tone levels are indicative of the lower meaning.

One of the factors affecting the distribution of duration inside a syntagm, or a phrase is place of localization of a logical emphasis. An emphasized syllable, as a rule, has the longer duration than a non-emphasized one. To perceive speech, a not insignificant role is played by the ratio of the durations of syllables in a word, of words in a syntagm, syntagms in a phrase, phrases in larger-than-the sentence unities that is connected with the speech tempo. Usually the tempo is determined by the ratio of the general duration of a segment to the number of syllables.

Being a relative value, the tempo has a certain linguistic meaning. It may indicate a degree of importance of a speech segment for the listener: the one, which bears the larger informative load, is pronounced in the slower tempo than the insignificant information. Such universal trend is noted and experimentally proved in many languages where syntagms with a large notional weight require much time for the pronunciation. For example, it is found that parenthetic units in the French, Kazakh and Russian languages in the preposition are pronounced in the slower tempo that is indicative of their maximum notional load in this position, and in the interposition and the postposition they are characterized by the quicker tempo that is indicative of their secondary load in the composition of a sentence. Imperative sentences in the languages so researched as compared to the declarative 
ones are most often characterized by the slow tempo of pronunciation, since it is important for the speaker that his willingness should be executed, and it especially relates to sentences with the meaning of an order. One of the important intonational components is a pause. The pause is a temporary stop, an interruption in the sounding and at the same time it is semiotic means performing a certain semiological function. According to their purpose, pauses may be physiological, emotive, intellectual, situational, etc. (Tseplitis, 1974). According to N. D. Svetozarova, a pause between the words performs language functions being: 1) Means of division of speech into intonational and notional units; 2) Aeans of expression of the character of a link between the parts of an utterance; 3) Means of notional and emotional accentuation of a word, or a syntagm (Svetozarova, 1993).

In addition to the actual and supposed pauses, there are voiced pauses of hesitation, which may be regarded as means of the current control of to avoid errors in speech, to think over the next following phrase. It has been established that the prosody exerts a direct influence on the semiological function of voiced pauses. Thus, for example, if the tone is low-falling, the voiced pause expresses consent, and if it falls from the higher initial pitch, then the consent acquires an emotive colour, and if sounds are pronounced in a rising tone, then a question is meant, etc. (Dolgova, 1974).

It is noted that the respiratory pause as an indicator of a speech product-a text, a discourse, and a pause in the sounding is also a sign of the disturbed semantic, grammatical, or other (semiotic) coherence of elements of the complex notional whole. When analyzing the syntactic environment of pauses, the following regularities are identified, which are, from our point of view, universal for many languages: the respiratory pauses may divide: 1) A subject and a predicate of the communicative unit; 2) Homogeneous predicates, or parts of the composite predicate; 3) A predicate and an object; 4) A predicate and an adverbial; 5) A predicate and an adjective; 6) There is also a frequency usage of a certain kind of lexico-semantic localizers, which positionally present the said pauses. In relation to the lexico-semantic environment of pauses, it is found that in the postposition the pauses may include various, often grammatically desemantized, lexical elements called lexico-semantic localizers (signs) of the communicative (communicative tasks and intentions), lexical (lexical meanings of the syntagm elements), grammatical and logical and semantic (extra-syntactic organization and semantics of grammatical relations and logical interrelations between the syntagm elements) levels. Such localizers may include: 1) Coordinating conjunctions; 2) Subordinating conjunctions; 3) Desemantized elements and particles; 4) Personal pronouns (Krivnova, 1995). The study of the pausing in the automatic speech synthesis is deemed to be promising and interesting (Krivnova, 1998).

For today, the objective to generate a neutral variant of intonation division and the related physical pausing for each sentence in a text is of current interest first of all (Monaghan, 1990). As is known, in many languages, the intonationally substantial limits turn to be unmarked punctuation marks, and many punctuation marks are put where there are no intonation limits. Intensity as an intonation component is usually considered in combination with other intonational means. There is a close link between the emphasis and the intensity. Syllables bearing a logical emphasis have, as a rule, the greater intensity value though the intensity is not the single emphasis component. The stress of a syllable is also ensured by the other phonetic means: the pitch and the duration.

According to T. M. Nikolayeva, the "logical emphasis" is meant to be an accentual embodiment of the latent presuppositional category, and an ability to create a special context aura and an organizing utterance in general. The logical emphasis is considered by Nikolayeva in connection with the theory of accentuation, the same being realized in the question-answer unity, in the actual division, in the certainty-uncertainty category, and in the idea of contrast and importance, which are presented by the prosodic means, among which the dynamic parameters are of paramount importance (Nikolayeva, 1982).

Differences in the form of a dynamic contour may convey information on the semantic weight of a syntactic structure in the composition of a sentence. Thus, it is parenthetic structures that are usually characterized by the decrease in the general level of the intensity that is deemed to be a universal feature for the most languages. The intensity in all languages rises with increase in the general emotional colour. One of the intonation components conveying human emotions is a prosodic timbre. Due to the timbre, emotional shades are distinguished such as joy, anger, tenderness, contempt, discontent, irony, sadness and others (Zinder, 1974).

For example, in the field of dramatic reading, N. V. Cheremisina notes the two main classifications of timbres: 1) Metal timbre (the head resonator functions) - timbre of slogans, appeals typical of the meeting speech and the reading of heroic verses; 2) Velvet timbre (the chesty resonator functions) - timbre of intimate, sweet speech, and of confessionary lyrics etc. (Cheremisina-Yenikolopov, 1999).

Being the means to convey emotive meanings of an utterance, the prosodic timbre may have a meaning too. In case of the equal verbal composition of an utterance, the timbre colour may differentiate the utterance's positive 
or negative meaning (Fries, 1964). In the expression of intonation categories, prosodic means in different languages act in various combinations. The intonational specificity of a language makes itself evident in the choice of prosodic means and in their interrelationship (Romportl, 1973). Interrelations of intonation components may be universal for all languages and specific for a language. A question of the presence of prosodic universals in a language has been discussed for a long time. Already V. N. Vsevolodsky-Herngross wrote that "in all individualization, there is something between all intonations that allows us to understand each other even when we do not understand a foreign language" (Vsevolodsky-Herngross, 1922).

According to L. A. Kanter, "The building of a contrastive-comparative and typological model of prosodic systems of the languages under consideration is based on the results of modeling speech intonation of each of the languages so compared. In this respect, one should bring to the forefront the task to compile inventory and classification of phrasal intonemes (prosodemes) of a language and their variants being that initial material, which needs to be compared, or, as is common to say, to be measured in the linguistic and metrological meaning of a word" (Kanter, 1988). I. G. Torsuyeva points to the fact that the typological classification of the language group intonation (kindred and non-kindred languages) is a part of general typology. According to Torsuyeva, the typological intonation analysis includes the following stages:

1) To choose inventory of units subject to their functions.

2) To choose relevant features to characterize units.

3) To describe the rules for interrelation and functioning of units in the formation of structures.

4) To describe the rules for the realization of units and structures (Torsuyeva, 1979).

At the same time, a question of the presence of prosodic universals in a language is widely discussed in the modern linguistics. The universality of the prosodic level is stated in the D. Bolinger's works "All the world's languages use voice modulations - there are no languages where one whispers more often than he speaks. It may turn out that in a number of languages, which are still to be analyzed, melodic fluctuations may be casual in principle. However, a language of such type will generally turn out to be so exclusive that it will be even not able to testify against the universality, which is understood widely. Thus, it is difficult to doubt in the intonation universality" (Bolinger, 1972).

\section{Conclusion}

The study of the speech intonation in different languages testifies that many established facts increase the sphere of the universal notion, and a growing number of intonation facts transfer from the private language notion to the common language notion. Prosodic features of languages are transparent, and the language contact may result in the impact of one language system on the other and in the prosodic field. Therefore, the intonologists think that facts perceived as specific so far, being organized into the system may lose their aura of specifity, whereby it will become possible to build a general model of intonation types not attached to some specific language. A further research in the field of the intonology may be conducted in view of a typological research of the intonation of kindred and non-kindred languages to find out typological rand all-purpose features in their intonational structure. It should be noted that the problems associated with the study of language universals have always held a prominent place in the linguistics and studied at all levels of the language system. Universals in the field of intonation are studied the least of all, though some linguists offer an opinion that the intonational level must be of general-purpose at its core. Some general features of the intonation of different languages can be explained, apparently, by the international character of the thinking of all people, and the intonation, as compared to other linguistic phenomena, associated with the meaning to a greater degree. As it is seen from our research, according to the formal matter, the Kazakh intonation has its own specific features differ it from other languages. Typological works in the field of intonation is, undoubtedly, of value both on the theoretical level - in the development of the universality and intonology, and on the practical level: in the teaching and the instruction of an intonation belonging to another language.

As the experimental data show on the basis of material from different languages, a set of prosodic features (nuclear tone frequency, duration, intensity) that differentiate sentences according to the purpose of an utterance, is universal. An increase in the intensity is often related to the automatic increase in the nuclear tone frequency, since both features are conditioned by the general physiological mechanism - the increase in the subligamentous pressure. The intonation universality is caused by the general physiological reasons, and the properties of the human organs of articulation. A set of prosodic features (melodics, tempo, pause) may be deemed to be universal to convey sense relations between syntagms as well as a downturn on the last word of a syntagm for the closing melodics, and an upturn at the end of a phrase for the uncompleted one. The accelerated tempo in many 
languages conveys information of less importance, and the slow tempo-more important information. In many languages, there are intonation meanings such as opposition, introduction, explanation, enumeration, logical accentuation, which are conveyed by the same prosodic means but only in various combinations thereof. The universality of emotional colours appears in general intonation characteristics of positive and negative emotions. Positive emotions are, as a rule, characterized by the higher tone registers unlike the negative ones, which have the lower tone level. Those words, which bear emotional load, are pronounced with the higher melodic melodic tone.

\section{References}

Alkon, P. K. (1959). Joshua Steele and the melody of speech. Language and Speech, 2.

Bolinger, D. (1970). Relative height Prosodic Feature Analysis. In Analyse des faits prosodiques. Studia Phonetica.

Bolinger, D. (1972). Intonation as a universal. Principles of typological analysis of languages refered to different order: Collected works under the editorship of B. A. Uspensky. Moskow.

Cheremisina-Yenikolopova, N. V. (1999). Laws and Rules of the Russian Intonation. In Study Guide. M.

Danesh, F. (1960). Sentence intonation from a functional point of view. Word, 16.

Dolgova, O. V. (1974). Halting Speech Semiotics. Moskow.

Fries, C. (1964). On the intonation of "Yes-No" question in English. In honor of Daniel Jones. London.

Hart, J. T. (2006). A Perceptual Study of Intonation. Cambridge Academ.

Kanter, L. A. (1988). System Analysis of Speech Intonation. Moskow.

Krivnova, O. V. (1995). Perceptual and semantic meaning of prosodic seams in a connected text. In L. L. Kasatkin (Ed.), Problems of Phonetics/Executive Editor. Moskow.

Krivnova, O. V. (1998). Automatic synthesis of the Russian speech for an arbitrary text. Works of international seminar for computer linguistics and its applications. Tarusa.

Monaghan, A. I. (1990). Rhythm and stress shift. Computer Speech and Language, 4. http://dx.doi.org/10.1016/0885-2308(90)90024-Z

Nikolayeva, T. M. (1982). Accentuation Semantics. M.: "Science”.

Romportl, M. (1973). Intonological typology. Studies in Phonetics. Prague.

Svetozarova, N. D. (1982). Intonational System of the Russian Language. Leningrad.

Svetozarova, N. D. (1993). Pause. Linguistic Encyclopaedic Dictionary. Moskow.

Torsuyeva, I. G. (1979). Intonation and meaning of an utterance. Moskow.

Tseplitis, L. K. (1974). Speech Intonation Analysis. Riga.

Vsevolodsky-Herngross, V. N. (1922). Theory of Russian Speech Intonation.

Zinder, L. R. (1974). General Phonetics. Leningrad.

\section{Copyrights}

Copyright for this article is retained by the author(s), with first publication rights granted to the journal.

This is an open-access article distributed under the terms and conditions of the Creative Commons Attribution license (http://creativecommons.org/licenses/by/3.0/). 